\title{
The Current Situation and Future Prospects of Simulators in Dental Education
}

Yaning $\mathrm{Li}^{1,2,3,4,5^{*}}$, BDS; Hongqiang Ye $\mathrm{e}^{1,2,3,4,5^{*}}$, DDS, PhD; Fan Ye ${ }^{6}$, BE; Yunsong Liu ${ }^{1,2,3,4,5}$, DDS, PhD; Longwei $\mathrm{Lv}^{1,2,3,4,5}$, DDS, PhD; Ping Zhang ${ }^{1,2,3,4}$, PhD; Xiao Zhang ${ }^{1,2,3,4,5}$, DDS, PhD; Yongsheng Zhou ${ }^{1,2,3,4,5}$, DDS, PhD

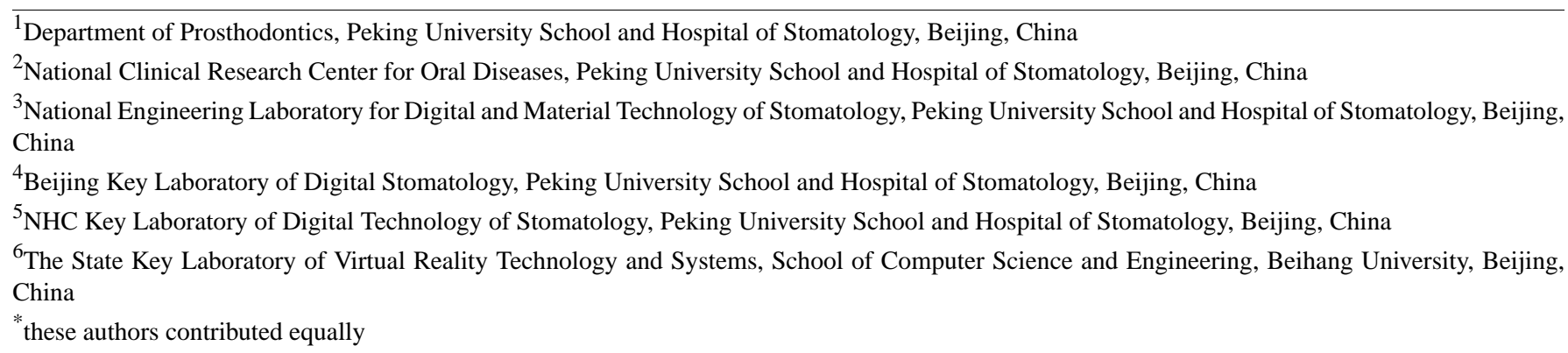

Corresponding Author:

Yongsheng Zhou, DDS, PhD

Department of Prosthodontics

Peking University School and Hospital of Stomatology

22 Zhongguancun South Avenue, Haidian District

Beijing, 100081

China

Phone: 8601082195070

Email: kqzhouysh@hsc.pku.edu.cn

\section{Abstract}

The application of virtual reality has become increasingly extensive as this technology has developed. In dental education, virtual reality is mainly used to assist or replace traditional methods of teaching clinical skills in preclinical training for several subjects, such as endodontics, prosthodontics, periodontics, implantology, and dental surgery. The application of dental simulators in teaching can make up for the deficiency of traditional teaching methods and reduce the teaching burden, improving convenience for both teachers and students. However, because of the technology limitations of virtual reality and force feedback, dental simulators still have many hardware and software disadvantages that have prevented them from being an alternative to traditional dental simulators as a primary skill training method. In the future, when combined with big data, cloud computing, 5G, and deep learning technology, dental simulators will be able to give students individualized learning assistance, and their functions will be more diverse and suitable for preclinical training. The purpose of this review is to provide an overview of current dental simulators on related technologies, advantages and disadvantages, methods of evaluating effectiveness, and future directions for development.

(J Med Internet Res 2021;23(4):e23635) doi: 10.2196/23635

\section{KEYWORDS}

dental simulator; dental education; virtual reality

\section{Introduction}

Dental skills training is a very important part of preclinical learning in dental education and has a long history [1]. Pioneers of dental education began to use extracted teeth in dental skills education in the 1800s [2]. Later, Oswald Fergus invented the first phantom head simulator in 1894, which was used to teach oral anatomy and physiology to dental students [2]. Since then, the phantom head simulator has developed rapidly. Modern phantom head simulators include water spray, dental handpieces, and other necessary items [3], providing students with a more realistic environment for diagnosis and treatment. The dental simulator appeared in the 1990s [4,5] as a result of further research into methods of dental preclinical education, concern for patient safety, improvements in computer technology, and the inappropriateness of a clinical environment for the novice 
[1]. The arrival of the dental simulator marked a new era of dental preclinical education.

The dental simulator replicates both soft and hard oral tissues as well as providing a clinical diagnosis and treatment environment through virtual reality (VR). It also simulates the interaction force between the bur and the tooth, the mouth mirror, and soft and hard tissues through force feedback technology to reproduce the whole training process for dental clinical skills as closely as possible [6,7]. In recent years, the dental simulator has mainly been used for adult vocational training and university education [8].

Traditional preclinical dental skills training, which was based on a phantom head, extracted teeth, or plastic teeth $[9,10]$, is generally used for practicing tooth preparation, for which the processes are irreversible. The acquisition of extracted teeth becomes more and more difficult, and the sensory feedback of preparing plastic teeth is different from that of real teeth $[3,11]$. The dental simulator, simulating realistic clinical conditions via VR and force feedback, makes training reversible, repeatable, and environmentally friendly $[12,13]$. Training via a dental simulator is varied [14] since different training content and tooth positions are available. These can be displayed in 3D on a computer screen for real-time evaluation by and feedback from teachers.

\section{Technologies Included in Dental Simulators}

The dental simulator is a deep integration of computer and dental technology, mainly consisting of VR and force feedback technologies [15].

\section{Virtual Reality}

VR uses computer technology [16] to generate a digital environment similar to the real environment in the visual, auditory, tactile, and other senses [17], which is used in many different fields. The operator interacts with and feels feedback from the virtual objects using specialized equipment [18]. A complete VR system consists of a stereo display device, a motion tracking device, an input device, and a computing platform. The stereo display device is usually a head-mounted display (HMD; Figure 1) [19]; another type of stereo display is the Cave Automatic Virtual Environment (CAVE; Figure 2) [20]. HMDs are more widely used than CAVEs because HMD application is more flexible and requires less space.

Figure 1. Head-mounted display and body motion sensors.

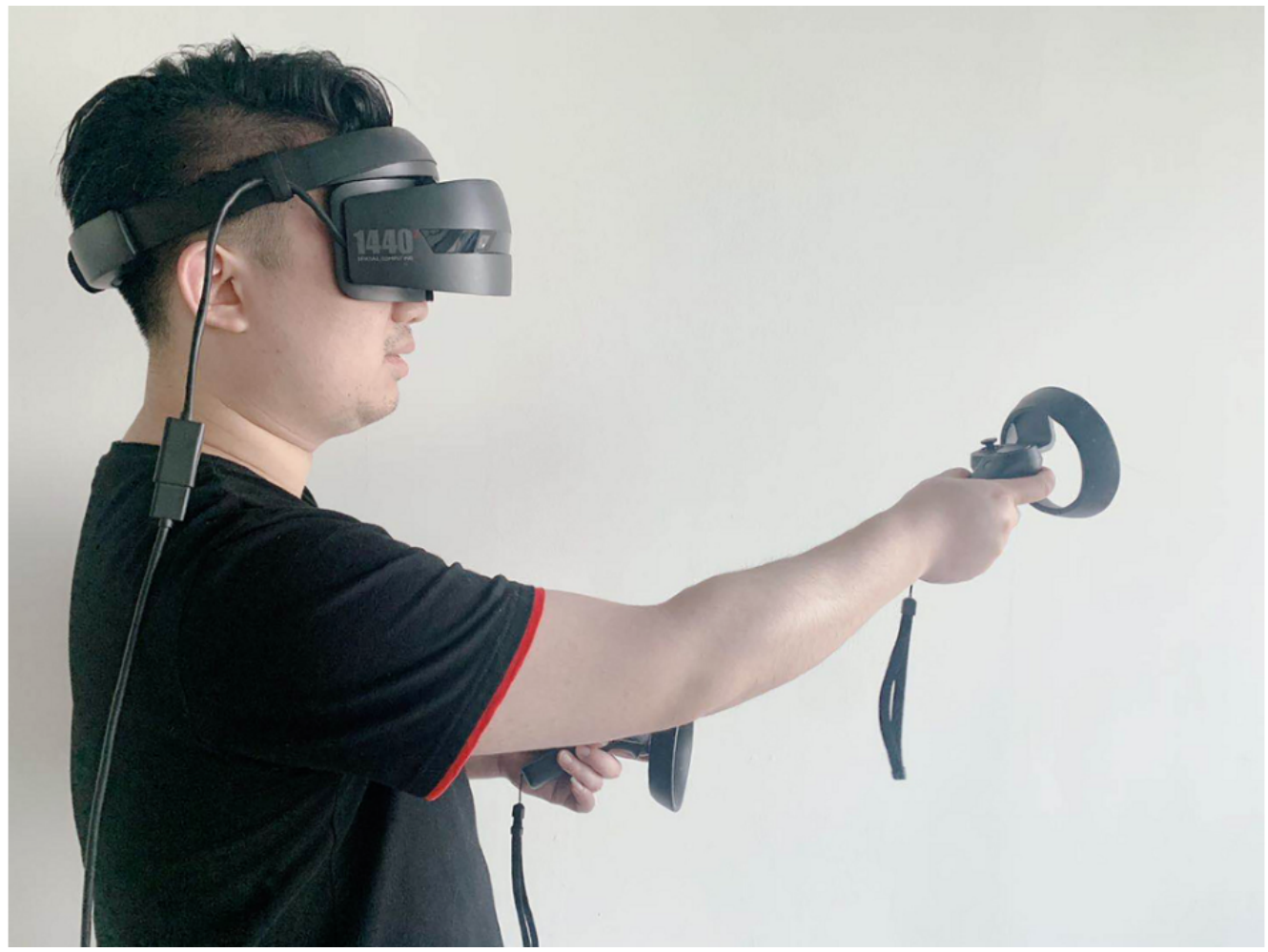


Figure 2. Cave Automatic Virtual Environment (CAVE).

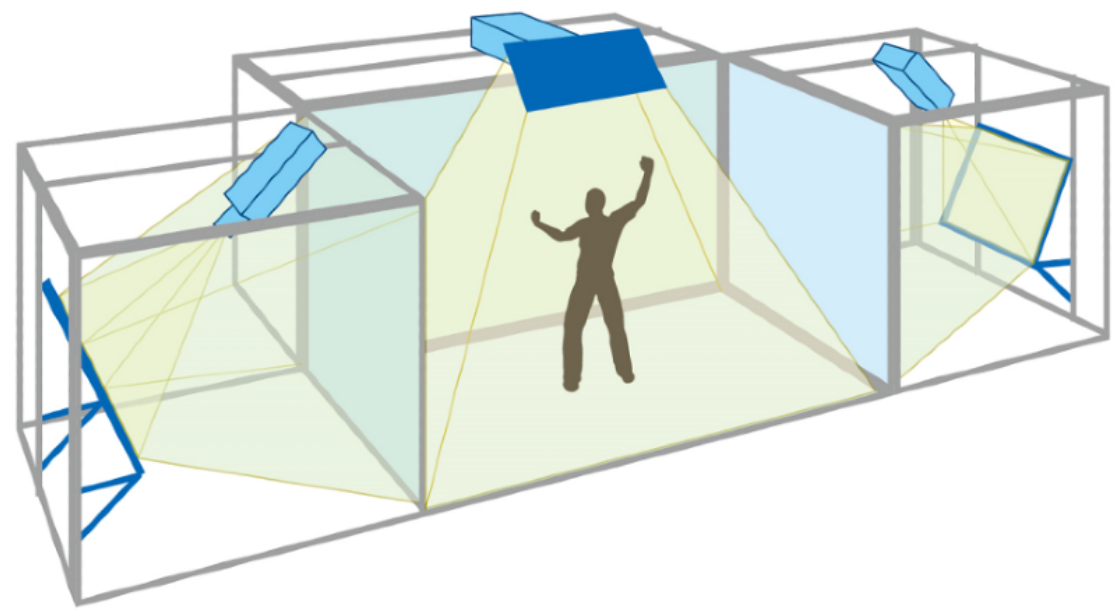

VR systems are divided into three immersive levels based on the degree of stimulated senses and interactions: nonimmersive system, semi-immersion system, and immersion system (Figure 3) [21]. A nonimmersive system only reproduces images on desktops; an immersion system places the user in a complete virtual environment with the support of several sensory output devices including visual devices such as HMDs, audio devices, and haptic devices [22]; and a semi-immersion system provides the user with a simulated environment between the two above.

Figure 3. Applications and immersive levels of virtual reality (VR) systems.

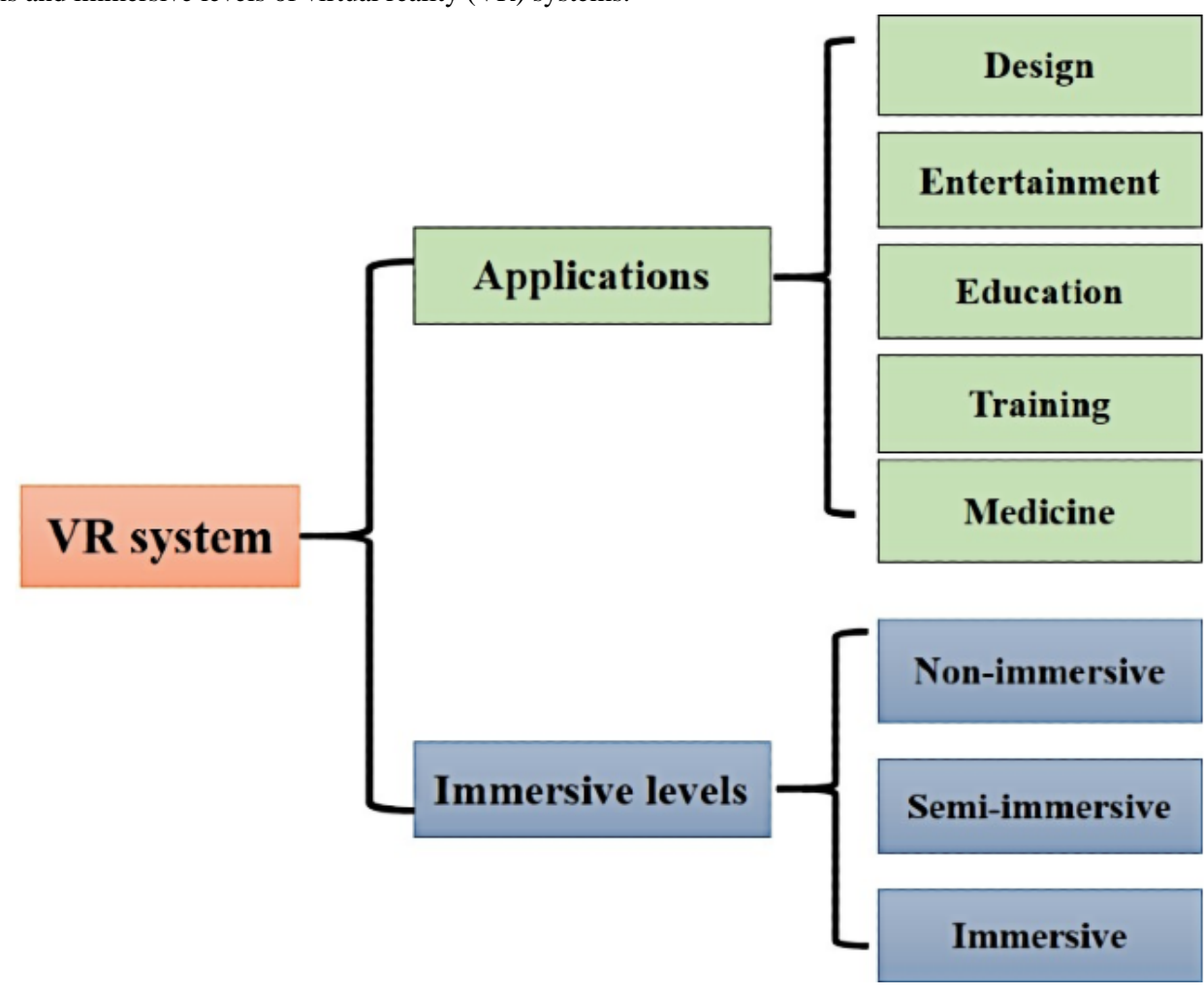

In the implementation of VR technology, the key points are modeling and interaction. In the medical field, images from computed tomography [7,23], magnetic resonance imaging (MRI) [24], and dental scanners [25] can be used to rehabilitate virtual models. Interactions mainly contain visual interaction and tactile sensation interaction, which are actualized by display device and force feedback device, respectively.

In the medical field, VR and related technology are gradually being applied in surgical training [26] and surgical navigation systems [27]. Combining VR with medical training is a new research field that has emerged with the development of computer science, sensor technology, and automation technology. A virtual operating environment with high fidelity and real-time performance can be created through virtual simulation technology [14]. The system is created and processed by a computer, with dedicated devices such as a helmet display and a force feedback handle that allow the user to observe and interact with the scene while experiencing multisensory feedback that give a near-realistic training effect [28]. 


\section{Force Feedback}

Haptic devices can receive and transmit motion signals to improve the operator's sense of reality [29], which is important for dental training assisted by VR.

To simulate the tactile sense of real dental training as much as possible, the reaction force of the virtual object is calculated using the appropriate force generation algorithm in the VR system [30]. Due to the characteristics of human touch receptors, real-time haptic rendering requires a refresh frequency of at least $1 \mathrm{kHz}$ [31]. For force feedback interaction in dental skills training, several kinds of interaction algorithms have been proposed for various scenarios, including teeth preparation, scaling, and bone drilling [32,33].

\section{Introduction to Existing Dental Simulators}

\section{Overview}

There is a wide variety of dental education simulators available, each with advantages and disadvantages in terms of training content, training process, hardware device, and software design. These are briefly described in Table 1 .

Table 1. Comparison of dental simulators.

\begin{tabular}{|c|c|c|c|c|c|c|c|c|c|}
\hline Characteristic & DentSim & $\begin{array}{l}\text { Virtual Ed- } \\
\text { ucation } \\
\text { System for } \\
\text { Dentistry }\end{array}$ & IDEA $^{\mathrm{a}}$ & Periosim & iDental & $\begin{array}{l}\text { Simodont } \\
\text { Dental } \\
\text { Trainer }\end{array}$ & VirTeaSy & IDEAL $^{b}$ & Voxel-Man \\
\hline \multicolumn{10}{|l|}{ Hardware facility } \\
\hline Display type & $\begin{array}{l}\text { 2D dis- } \\
\text { play+ } \\
\text { phantom } \\
\text { head }\end{array}$ & $\begin{array}{l}\text { 2D dis- } \\
\text { play+ } \\
\text { phantom } \\
\text { head }\end{array}$ & 2D display & $\begin{array}{l}\text { 3D glass- } \\
\text { es }+2 \mathrm{D} \text { dis- } \\
\text { play }\end{array}$ & 2D display & $\begin{array}{l}\text { 3D glass- } \\
\text { es+ } 2 \mathrm{D} \text { dis- } \\
\text { play }\end{array}$ & $\begin{array}{l}3 \mathrm{D} \text { glass- } \\
\text { es }+2 \mathrm{D} \text { dis- } \\
\text { play }\end{array}$ & $\begin{array}{l}\text { 2D dis- } \\
\text { play+ } \\
\text { phantom } \\
\text { head }\end{array}$ & $\begin{array}{l}\text { 3D glass- } \\
\text { es }+2 \mathrm{D} \text { dis- } \\
\text { play }\end{array}$ \\
\hline $\begin{array}{l}\text { Operation with two } \\
\text { hands }\end{array}$ & Available & Available & Available & Available & Available & Available & No & Available & Available \\
\hline Fixed finger rest & Yes & Yes & No & No & Yes & Yes & Yes & No & No \\
\hline Ergonomic postures & Yes & Yes & No & No & Yes & Yes & Yes & Yes & Yes \\
\hline \multicolumn{10}{|l|}{ Software design } \\
\hline Application field & $\begin{array}{l}\text { Tooth } \\
\text { preparation }\end{array}$ & $\begin{array}{l}\text { Crown } \\
\text { preparation }\end{array}$ & $\begin{array}{l}\text { Manual } \\
\text { dexterity } \\
\text { training }\end{array}$ & $\begin{array}{l}\text { Periodontal } \\
\text { training }\end{array}$ & $\begin{array}{l}\text { Periodontal } \\
\text { training }\end{array}$ & $\begin{array}{l}\text { Caries re- } \\
\text { moval and } \\
\text { crown } \\
\text { preparation }\end{array}$ & $\begin{array}{l}\text { Dental im- } \\
\text { plant } \\
\text { surgery }\end{array}$ & $\begin{array}{l}\text { Dental ra- } \\
\text { diography }\end{array}$ & $\begin{array}{l}\text { Dental } \\
\text { surgery }\end{array}$ \\
\hline Fundamental skills & Yes & Yes & Yes & Yes & Yes & Yes & Yes & Yes & Yes \\
\hline Clinical cases & No & No & No & No & Yes & Yes & Yes & Yes & No \\
\hline Exam simulation & Yes & Yes & No & Yes & Yes & Yes & Yes & Yes & Yes \\
\hline Repetitive practice & No & No & Yes & Yes & Yes & Yes & Yes & Yes & Yes \\
\hline $\begin{array}{l}\text { Practice at different } \\
\text { levels }\end{array}$ & No & No & Yes & No & Yes & Yes & Yes & No & Yes \\
\hline $\begin{array}{l}\text { Individualized learn- } \\
\text { ing }\end{array}$ & No & No & No & No & No & No & Yes & No & No \\
\hline Result evaluation & Yes & Yes & Yes & Yes & Yes & No & Yes & Yes & Yes \\
\hline Force feedback & Yes & Yes & Yes & Yes & Yes & Yes & Yes & Yes & Yes \\
\hline $\mathrm{VR}^{\mathrm{c}}$ immersive level & Non $^{\mathrm{d}}$ & Non & Non & Non & Non & Non & Non & Non & Non \\
\hline
\end{tabular}

aDEA: Individual Dental Education Assistant.

${ }^{b}$ IDEAL: Internet of Things-based dental education and learning.

${ }^{\mathrm{c}} \mathrm{VR}$ : virtual reality.

${ }^{\mathrm{d}}$ Non: nonimmersive.

\section{DentSim}

The DentSim system unit, consisting of a phantom head and dentoform, dental instruments, infrared sensors, infrared cameras, and two computers, was born in 1997 [34]. The infrared cameras can capture the orientation and movement of resin teeth and a handpiece so as to show the students' work virtually on the computer screen in real time. The unit allows students to see the evaluation of their tooth preparation compared with the ideal preparation on the screen, while also providing them the ability to continue working on the resin teeth [35]. The training using DentSim is more efficient and standardized than that using traditional preclinical teaching 
methods [36]. The disadvantage of this unit is that it relies on physical resin teeth, which are disposable consumables.

\section{Virtual Education System for Dentistry}

Virtual Education System for Dentistry is a dental simulator for prosthodontics developed by the Affiliated Stomatological Hospital of Nanjing Medical University and Suzhou Digital-health Care Company. The system contains the Virtual Learning Network Platform (VLNP) and Real-time Dental Training and Evaluation System (RDTES) [37]. Prior to practical work, students are requested to learn courses on the VLNP, including reading the operational instructions and predefined criteria of crown preparation and watching the standard operational videos. Afterwards, students can perform crown preparations on the phantom head under the guidance of the RDTES; the processes and results can be recorded by the RDTES. When the students finish their preparations, the RDTES can automatically assess the procedures and results of preparation based on the predefined tooth preparation criteria. As well, the students can visually compare their own procedures and results with the predefined assessment criteria on the computer screen $[37,38]$.

\section{Individual Dental Education Assistant}

Individual Dental Education Assistant (IDEA) is a VR hand flexibility training simulator consisting of a handheld stylus that simulates a dental handpiece and provides force feedback and a computer installed with simulation software. Unlike other dental simulators, IDEA is designed to enable students to be flexible and proficient in the use of dental handpieces by practicing removing predesigned virtual materials with different shapes (eg, straight line or circle). Therefore, IDEA aims to train dental students in hand flexibility, not to train students on a particular teaching component such as crown preparation or scaling. The main advantage of the system is its evaluation system. During the training process, two parameters determine the score obtained: drilling speed and drilling accuracy. Deviation from the trajectory or to an inappropriate depth can lead to a decrease in accuracy, and this is displayed as an accuracy bar on the screen. Complete depletion of the bar means that the student fails the test [39]. Some researchers have reported that IDEA could improve students' performance in the dental skill test; in addition, it can be used to identify students with troubles with hand flexibility at an early stage that may allow for early intervention to prevent failure [40,41].

\section{PerioSim}

PerioSim, consisting of a stereoscopic display, a computer, and a haptic device, allows students to use virtual dental instruments to visualize and detect caries and periodontal diseases in a haptic environment [12]. The system is available online for students and allows teachers to upload different training programs, which can be downloaded and replayed by students at any time, making this system convenient and efficient [35]. Steinberg et al reported that the image display and force feedback were very realistic for teeth and dental instruments but not for gingival tissue [42].

\section{iDental}

$i$ Dental is a periodontal skill education simulator developed by Peking University School and Hospital of Stomatology and Beihang University, which can simulate periodontal examinations and treatment procedures including periodontal probing and calculus detection and removal. Unlike PerioSim, the device mainly uses a 2D monitor. However, it is equipped with an odontoscope handle, so it can be used to practice two-handed cooperative operation, making it realistic. $i$ Dental also has a basic periodontal knowledge teaching module, which enables students to review basic knowledge before operation training. A combination of the two training parts improves the teaching effectiveness [43].

\section{Simodont Dental Trainer}

Simodont Dental Trainer is a widely used teaching simulator for dental skills training that is currently available in many dental schools. It mainly includes modules for hand flexibility, cariology, crown and bridge preparations, clinical cases, and a full mouth simulation experience $[13,44]$. One of the highlights of the system is that an X-ray of the working tooth is attached to each individual case, which can allow students to make a diagnosis assisted by both the appearance of teeth and the X-ray films [13].

The system does have some disadvantages. It requires 3D glasses for 3D display. Excessive training on a single tooth fails to create a realistic sense of manipulation. The training process for crown preparation is single-jawed and does not fully mimic the narrow operating space of the mouth. Besides, it cannot be used to train students about positioning requirements because operation postures during training are fixed and visual angle conversion requires manual rotation of the rotary button.

\section{VirTeaSy Project}

The VirTeaSy project is a dental implant training simulator and is composed of VirTeaSy Scan Implant and VirTeaSy Implant Pro. VirTeaSy Scan Implant is used for implanting scheme designs by students. Radiographs are used by students to perform the implant treatment plan, including the implant's characteristics (shape, diameter, length) and its location (location, angle, insertion depth) in the jaw. When the treatment plan is complete, it can be compared with the design planned by an expert that is stored in the database to identify where improvements could be made in their own plans. In addition, the device's database contains cases of varying difficulty, so students with different skill levels can use it to practice accordingly [45].

VirTeaSy Implant Pro is a virtual implant surgery training system, which allows students to perform surgery cases planned in VirTeaSy Scan Implant. VirTeaSy Implant Pro is supplemented by an auxiliary system that can alert students if the drilling's location, angle, and depth are incorrect as well as if there is overheating of the bone. In addition, the VirTeaSy Implant Pro has a display through which the teacher can interact with the student in real time and assist the student as necessary. VirTeaSy Implant Pro can improve students' skills in bone mineral density perception through force feedback, thus allowing them to perceive whether their bone density measurements in 
VirTeaSy Scan Implant match the reality [46]. VirTeaSy Scan Implant and Implant Pro complement each other, forming an efficient learning tool [45].

\section{Internet of Things-Based Education and Learning System}

The Internet of Things-based education and learning (IDEAL) system is an oral radiology education simulator. The simulator is mainly used for teaching students to take intraoral X-ray images without using X-rays. The IDEAL system consists of a simulator cone, simulator main body, sensor, detector, and stool. Training contents comprise basic education before X-ray imaging, information on X-ray imaging techniques (such as periapical radiography, bisecting angle technique, and paralleling technique), a test bank, and an evaluation and feedback system. During the training process, students can practice taking X-ray images for different tooth positions by adjusting the angle of the X-ray tube to improve their skills in taking X-ray images. At the end of training, students submit their own imaging results to the system and receive automatic feedback and evaluations from the system. The system allows students to avoid using radiographic devices while learning to take dental films, reducing the risk of radiation exposure to both students and patients. The system is safe and affordable [47].

\section{Voxel-Man Simulator}

The Voxel-Man simulator is a VR surgical simulator that primarily consists of a 2D monitor, simulated surgical operating handle, foot pedal, and 3D glasses. At present, the device is mainly used to simulate apical surgery, such as apical resection and apical cystectomy [48].

The system provides different training modes depending on the trainees' level, with different display interfaces and different operating instructions. The three modes to choose from are primary mode, advanced mode, and exam mode. In primary mode, the lesions and surrounding important anatomical structures (such as the alveolar nerve) are marked with bright colors. This not only helps operators to understand the anatomical characteristics of the corresponding surgical area, but also reminds them of the scope and amplitude of the operation at all times to help them avoid damaging these important anatomical structures. When the surgical instrument is close to an important anatomical structure, the system will emit a danger alarm. In advanced mode and exam mode, some of the functions and hints are turned off $[48,49]$.

In addition, the system can record the operation process for later replay so that the operator can identify errors and mistakes to improve on [48]. The operator can stop the operation at any time and can undo a wrong step or restart a new one, saving a lot of time. Cases vary in difficulty, allowing operators with different experience levels to practice.

\section{Advantages of Dental Simulators}

Compared to phantom-based traditional training methods, dental simulators have many strengths that will offer students a better learning environment. Besides dental operation skills, students are also able to acquire relevant theoretical knowledge through dental simulators [37]. Since the dental simulators allow repeatable and reversible preclinical training of clinical skills [50,51], they give students a more flexible training experience [14]. They also allow digital objective evaluation and tutorial feedback [34,52] by recording the training processes [53]. In addition, training in dental simulators is more clinically relevant [54] because they recreate situations that are similar to those encountered in a real clinical environment [14]. It is certain that dental simulators can eliminate the risk of treatment and enhance the safety of patients $[55,56]$. Previous studies showed that training using dental simulators can save the time of faculty $[50,57]$ and allow students to practice repeatedly whenever they want until they achieve mastery. Some studies reported that training in dental simulators can reduce training time compared with traditional training methods [57]. Therefore, the application of dental simulators in teaching can make up for the deficiency of traditional teaching methods and reduce the teaching burden, improving convenience for both teachers and students.

\section{Current Disadvantages of Dental Simulators}

The dental education simulators that have been described all have certain disadvantages in terms of both hardware and software.

\section{Disadvantages of Hardware}

\section{The Stereo Vision of the Display Is Not Visible Enough and the Resolution Is Not High Enough}

Currently, 3D displays in dental simulators are relatively behindhand. To achieve 3D display, most simulators use 3D glasses; these can slightly change the color of the oral tissues and can produce unpleasant effects such as vertigo and nausea [45,58]. In addition, 3D glasses change the image quality to a certain extent, reducing the resolution of the image. The display of oral tissue needs to be precise since the dental operation needs to identify subtle differences between different kinds of tissues, so a lower resolution may result in inaccuracy in the operation [59]. Image display can also affect the VR immersiveness, so it is necessary for researchers to find a higher resolution of $3 \mathrm{D}$ display to replace 3D glasses.

\section{No Fixed Physical Finger Rest}

A stable finger rest is of great significance in dental operations because of the small intraoral space and the requirement for precise dental operations $[15,43]$; without it, accidental injury to the surrounding soft and hard tissues may occur. Training on the use of finger rests is crucial in dental skills training, so finger rests should be provided for optimal simulation during dental skill training.

\section{Lack of Bimanual Cooperative Operation}

Bimanual operation is extremely important in dental operations. In general, the left hand of the operator manipulates an odontoscope to stretch and protect the soft tissues and reflect light, to ensure accurate and safe intraoral manipulation of the instrument held in the right hand. For optimal simulation of an operation on a real patient, training on bimanual operation in a dental simulator is essential $[53,60]$. 


\section{Disadvantages of Software Design}

\section{Simulation of Force Feedback Is Not Realistic Enough}

In clinical operations, dentists continually judge the process to determine whether to continue the operation by perceiving the different force feedback of the different oral tissues. Therefore, the fidelity of force feedback in the simulator is vital to dental training [27]. At present, the force feedback of oral simulators is based on a force-generating algorithm. This is different from the force feedback of a real instrument in contact with the oral tissue, especially soft tissue. Consequently, researchers need to work on improving the fidelity of force feedback in the future [14,61].

\section{Simulation of Soft Tissue Deformation Is Not Realistic Enough}

An oral environment simulation includes simulation of tongue and facial tissue deformation [62]. When a simulated surgical instrument collides with the deformable object, the object needs to deform accordingly. Deformation simulation is based on the physical properties of the soft body, such as density and elasticity. To express these properties, a physical model must be established; these commonly include the mass-spring method $[63,64]$ and the finite element method [65]. The mass-spring method is simple and commonly used, but it is hard to maintain tissue volume information and set the stiffness of the spring.
The drawback of the finite element method is that it is hard to use in real-time simulation [65]. Therefore, a physical model with higher calculation efficiency and more accurate simulation that can better represent the physical characteristics of oral tissues needs to be established.

\section{The Training Content Is Insufficient}

At present, many dental simulators do not have different degrees of difficulty in training, so students cannot learn step by step in the process of training. Moreover, the simulators have only basic skills training and lack the application of skills in clinical cases, so they cannot assess students' progressive mastery of skills. More comprehensive and systematic training content should be developed in the future [15].

\section{The Evaluation of Training Results Cannot Be Accurately Quantified}

It has been reported that professional instruction and performance feedback are beneficial for students' skills acquisition [66,67]. Some simulators cannot give an accurate quantitative evaluation of the student's operational results after training, so students do not know whether their operation results meet the requirement or not.

In summary, a good dental skills training simulator should be able to overcome these shortcomings, and its comprehensive features are summarized in Figures 4 and 5.

Figure 4. Hardware facilities required for a dental simulator. CAVE: Cave Automatic Virtual Environment; HMD: head-mounted display.

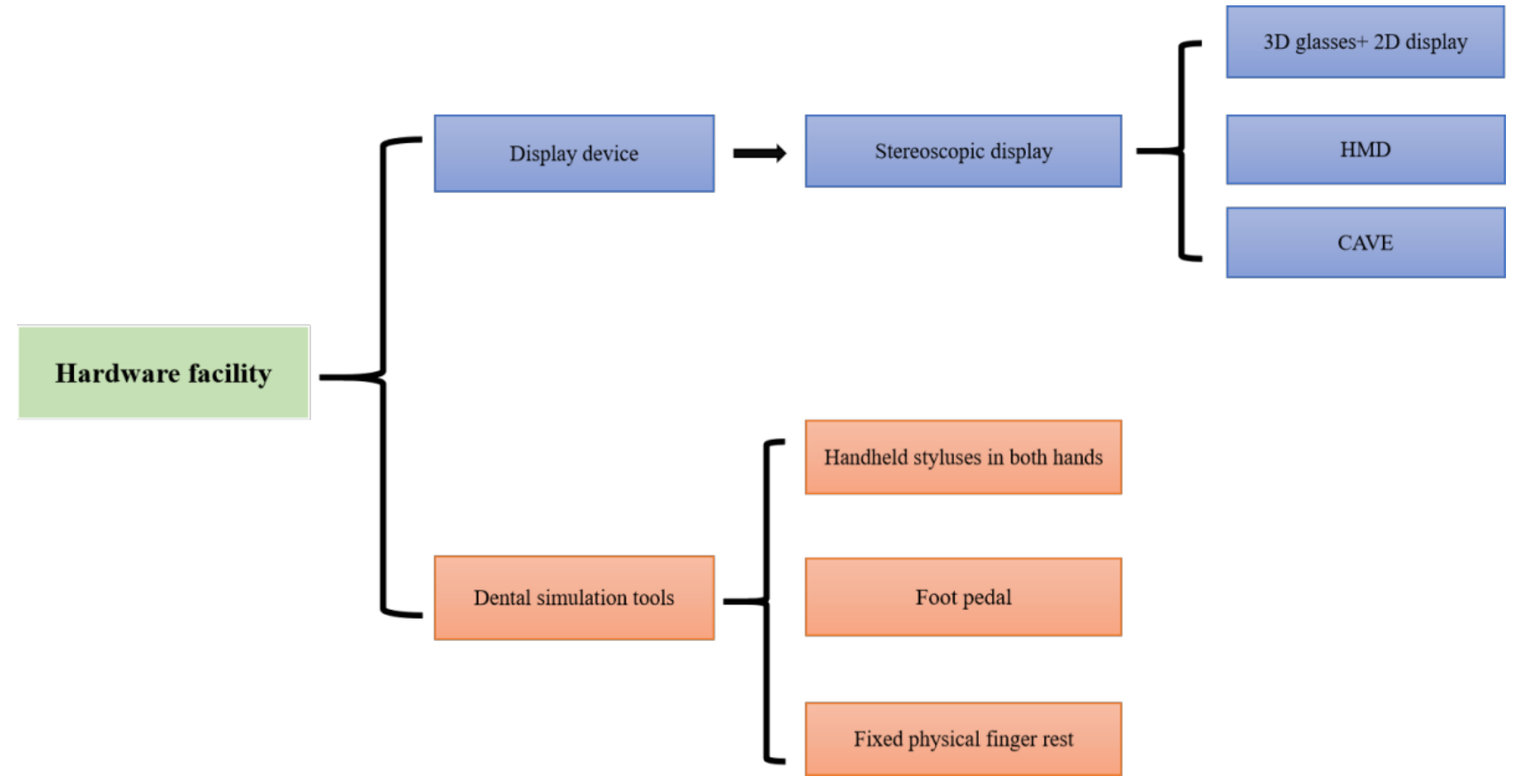


Figure 5. Software design required for an ideal dental simulator.

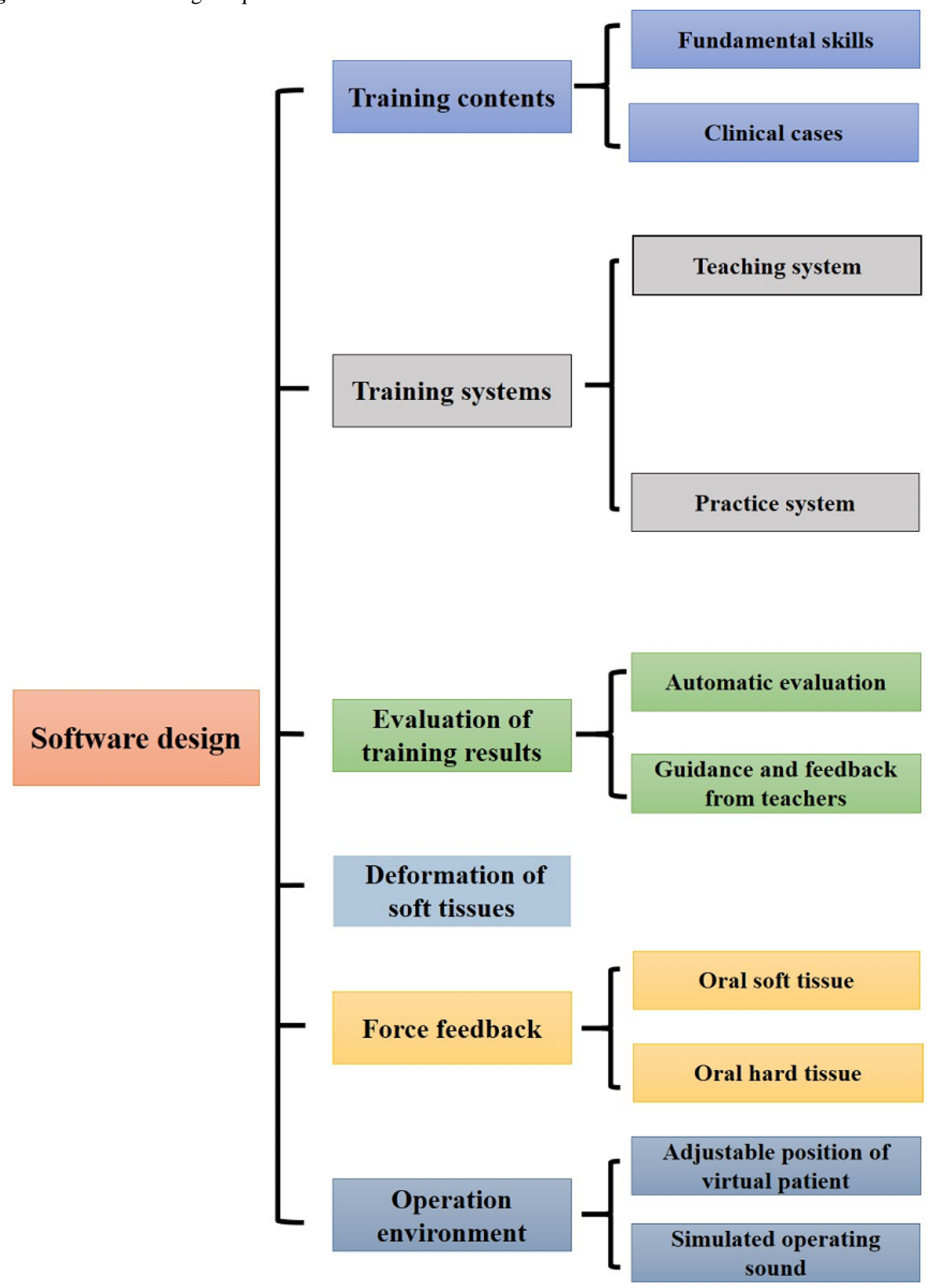

\section{Effectiveness Evaluation of Dental Simulators}

\section{Methods for Effectiveness Evaluation}

The effectiveness of VR systems can be evaluated using two analytical methods, qualitative and quantitative [15,43], which can be analyzed by questionnaires and comparative studies, respectively.

\section{Questionnaires}

Questionnaires are mainly used to investigate the subjective experience of people using the equipment, providing possible ways to improve the next iteration of the simulator. The content of the questionnaire is mainly based on the relationship between the user and the simulator. The simulator has two categories of users: trainers and trainees. For trainers, the device is a teaching tool and therefore needs to be evaluated for its auxiliary role in teaching, such as whether it reduces teaching cost or improves teaching efficiency. For trainees, the device is a learning tool and needs to be evaluated for learning effectiveness and construction of a learning environment [68]. Therefore, the content of the questionnaire should be designed according to the characteristics of the respondents.

The content of the questionnaire is mainly classified into two categories. The first category is the evaluation of the software and hardware of the device, involving force feedback, 3D modeling, the ease and convenience of using the device, the simulation degree, and the design of the device. Wang et al proposed a qualitative evaluation architecture based on the analysis of function components, which included the performance and usability of the simulator [15]. The second 
category is the evaluation of the teaching effect of the device, which involves the subjective evaluation of the equipment effect by users [69]. The main questions in such questionnaires are whether the students think that the simulator assisted their study, improving their understanding of the related curriculum, and whether they are willing to use the simulator in their future study [70]. In addition, Venkatesh et al made the Unified Theory of Acceptance and Use of Technology questionnaire proposal to measure the acceptance of a new technology [71], and Bravo et al applied it to the use of dental simulators and concluded that it can assess the acceptance of dental simulators in dental education [72].

\section{Comparative Studies}

Comparative studies are mainly suitable for quantitative evaluation of objective function of a simulator, such as evaluating the role of the simulator in education compared with traditional teaching methods [73,74], the accuracy of the simulator at evaluating different kinds of trainees [46,75], and its accuracy in predicting the skill levels of students [76]. Barsom et al proposed a matrix of validity type to train medical professionals and classified the existing research methods including surface validity, content validity, construct validity, concurrent validity, and predictive validity $[77,78]$.

Construct validity is the most widely used criterion in the functional evaluation of simulators [79]. The objects of the study of construct validity are populations with different clinical experience and skills in a corresponding specialty, such as experts and students [80]. By comparing the relevant parameters of using the simulator in different groups, construct validity of the simulator aims to distinguish different levels of dental skills. Dental trainees with diverse training time in a study by Mirghani et al [75] and dental students in their first year and experienced dentists in a study by Eve et al [45] were chosen to be trained using the simulator to evaluate its construct validity.

\section{Influence Factors}

Dental skills training takes the form of gradual acquisition, so the proficiency of training using the simulator can improve along with increasing familiarity with the training content. Urbankova et al concluded that repeating the training led to learning the test content, which could affect the results of the study [40]. Since VR is a new technology, teachers' sensitivity to the simulator may depend on their age, which could affect the results of the experiment. Therefore, questionnaires are often designed to eliminate the influence of these two factors [81].

Training and demonstration before the experiment, which allow objects to know the experimental flow and operational specification and eliminate the interference factors, are necessary [47]. Seymour et al tested trainees' visual ability, perception ability, and mental condition to exclude interference factors that affected experimental results [82].

\section{Effectiveness of Dental Simulators}

To date, many pilot tests have been conducted to evaluate the validity of dental simulators in endodontics $[3,83]$, periodontics $[12,42,43,84,85]$, oral and maxillofacial surgery [65,86-88], dental radiography [41], prosthodontics [37,59,85], implantology [89,90], and orthodontics [90]; the specific applications of dental simulators in dental education are summarized in Table 2.

Table 2. Applications of dental simulators in dental fields.

\begin{tabular}{|c|c|}
\hline Dental fields & Training contents \\
\hline Endodontics & $\begin{array}{ll}\text { - } & \text { Dental caries detection } \\
\text { - } & \text { Caries removal } \\
\text { - } & \text { Light-curing skills } \\
\text { - } & \text { Endodontic cavity preparation }\end{array}$ \\
\hline Periodontics & $\begin{array}{ll}\text { - } & \text { Periodontal probing } \\
\text { - } & \text { Calculus detection and removal } \\
\text { - } & \text { Ultrasonic scaling }\end{array}$ \\
\hline Oral and maxillofacial surgery & $\begin{array}{ll}\text { - } & \text { Dental anesthesia training } \\
\text { - } & \text { Maxillofacial palpation } \\
\text { - } & \text { Dental extraction skills } \\
\text { - } & \text { Orthognathic surgery } \\
\text { - } & \text { Dental surgery }\end{array}$ \\
\hline Dental radiography & Intraoral X-ray imaging \\
\hline Prosthodontics & Tooth preparation \\
\hline Implantology & $\begin{array}{l}\text { - Implanting scheme design } \\
\text { - } \quad \text { Implant drilling skills }\end{array}$ \\
\hline Orthodontics & Training and treatment planning in orthodontics \\
\hline
\end{tabular}

Many researchers are positive about the roles that dental simulators play in skills training. Al-Saud et al reported that students could gain basic manual dexterity at a quicker pace when they practiced skills with the guidance of experienced faculty, and training with dental simulators helped students to retain the skills they had learned [91]. A study performed by Plessas showed that students could develop a better understanding of the material by using dental simulators since they create a more varied learning environment compared with traditional training methods [74]. Suebnukarn et al evaluated 
the effectiveness of dental simulators in cavity preparation and concluded that haptic VR simulators are equivalent to conventional dental phantom heads in reducing operation errors [92]. Other research provided evidence that students can improve their tooth extraction skills [93], dental radiology skills [47], and implant skills [32,90] through dental simulators. Dental simulators were also reported to be able to enhance students' confidence [94] and improve their attitudes toward patients [53] and abilities to discern and solve medical emergencies [70,95,96]. Some studies focused on students' acceptance of dental simulators and found that most students are willing to learn with dental simulators, which would boost their enthusiasm to learn [97]. Therefore, many research studies indicated that dental simulators had the potential to be an alternative to conventional training methods $[36,52,98]$.

However, as mentioned above, there are still some disadvantages of dental simulators that can't be ignored, and these disadvantages may directly influence the effectiveness of dental simulators. In addition, the effectiveness of some dental simulators has not been validated [88,98]. Therefore, it is suggested that dental simulators cannot completely replace traditional skill training methods. The automated evaluation and tutorial feedback offered by dental simulators are considered to be complementary components to traditional methods [84]. Some studies concluded that a combination of traditional and virtual methods would be an optimal approach to choose in skills training [52,99,100].

\section{Prospects of Dental Education Simulators}

Current simulators are deficient in stereovision, video resolution, force feedback, instructional content, and outcome assessment; in response to these issues, we offer an outlook for their future development.

\section{Visualized Analyses of Education Data Based on Big Data Technology}

By applying big data technology to medical education, we can establish statistical models by the visual analysis method [101] via educational data mining and learning analysis [102], which allow trainers to analyze and understand the learning status of trainees intuitively. Currently, big data technology has been applied in educational analysis of massive open online courses [103] and learning effectiveness prediction for medical courses [101].

A similar big data analysis platform can be set up in dental skills training. We can collect dental operation data and establish a database of correctly performed operations. Then, a scientific evaluation system to score the training results by comparing them with the correctly performed operations can be created. Trainers can identify information on general problems in operations, as well as problems experienced by the individual trainee, to analyze and predict trainees' ability to master the skills, error-prone points, and the pass rate of examinations. Based on the analysis, trainers can create or adjust different plans for all trainees to enhance their learning experience and performance. Therefore, the combination of big data and education will make it possible to deeply understand and study the training process in order to provide more trainees with quality training.

\section{Video Transmission With Quicker Speeds and Less Delay Supported by 5G}

The development of 5G technology will allow transmission links with high bandwidth and low delay [104-106]. In the virtual oral training system, calculations are often performed on the server side to improve accuracy. The use of $5 \mathrm{G}$ technology will greatly increase the transmission rate of high-definition video data from the server host to the display device, reducing the response delay [107-109]. This will provide users with more reliable visual and tactile feedback and improve comfort [110].

Currently, the $5 \mathrm{G}$ quality of experience framework is proposed to solve the problem of transmitting ultra-high-definition video on the 5G network [111]. This could provide a basis for the establishment of a VR dental educational video network. Large-scale synchronous training and one-to-one demonstrations could be performed via $5 \mathrm{G}$ transmission to improve training efficiency.

\section{Improvement of the Simulation of Force Feedback by Deep Learning}

Deep learning techniques are widely used to find rules from a large amount of data, abstract problems through neural networks, and establish input and output mapping.

In the field of haptics, deep learning has been used to obtain haptic properties of objects from their images [112], whereby force feedback devices can directly generate a sense of force feedback that mimics the real physical properties without having to manually adjust physical parameters.

We can use deep learning to obtain the force feedback properties of teeth and build different deep learning models for different parts of the teeth. Therefore, the instrument would have different force feedback in contact with normal teeth, dental caries, tooth enamel, dentin, and other areas.

Deep learning can also play a role in oral modeling. Now, deep learning has been widely used in medical image analysis and modeling [113]. Through this type of method, we can easily extract relevant regions from computed tomography or MRI data and reconstruct mesh data [114]. These technologies can be transferred to oral cavity modeling, which can greatly facilitate model construction in a virtual surgery system and quickly establish a personalized oral cavity model.

\section{Improvement of the Immersiveness of Dental Simulators by Augmented Reality}

Augmented reality technology is an extension of VR technology, combining virtual images with real environments to support interaction with virtual objects in real time.

Nowadays, augmented reality technology has begun to be used in the medical field. Based on an augmented reality helmet (HoloLens by Microsoft), various applications have been developed such as surgical navigation applications [115] and intelligent medical management systems [116]. HoloLens also 
supports a display of high-definition video derived from high-performance computing.

The virtual tooth and the phantom head can be combined with augmented reality technology in a dental training system. Students can feel the phantom head directly with their hands and interact with a virtual tooth through a force feedback device. At the same time, high-definition images allow users to observe finer tooth details, which can greatly improve the reality and the immersiveness of the experience. The users can also observe patients from multiple views, which will greatly enhance the trainees' understanding and learning of training objectives $[117,118]$. Therefore, augmented reality will have a significant effect on dental education in the future.

\section{Strengths and Limitations}

The strengths of this paper are as follows: First, we have come up with a summary of comprehensive features that a good dental simulator should possess based on the analysis of the advantages and disadvantages of current dental simulators. Second, this paper proposes the future prospects of dental simulators and provides researchers with new ideas for further studies.
Our paper also has some limitations. First, our paper lists the nine dental simulators that are commonly mentioned and studied in most articles instead of all kinds of dental simulators, which may have a little effect on the results of our study. Second, our study is focused on VR- and haptic-based dental simulators; as a consequence, some relevant papers may not be included due to inappropriate use of keywords.

\section{Conclusion}

Despite the fact that dental simulators are not currently able to rival traditional training modalities for skills training in some disciplines, they still have some advantages over traditional methods, and their effectiveness has been validated in some cases. More studies should be conducted to improve the force feedback, video transmission, and immersiveness of dental simulators. With scientific and technological development, dental simulators that gradually combine with big data, cloud computing, 5G, and deep learning technology will offer students individualized learning assistance, and their functions will be more diverse and suitable for preclinical training.

\section{Acknowledgments}

This work is supported by the Teaching Reformation Fund of Peking University School and Hospital of Stomatology (2018-ZD-04, HY; 2019-ZD-07, Y Liu), and all authors thank Beijing Unidraw VR Technology Research Institute Co Ltd for providing Figure 1.

\section{Authors' Contributions}

Y Li and FY designed the structure of this manuscript and wrote the paper; Y Liu, LL, PZ and XZ collected the data and revised the manuscript; and HY and YZ conceived and revised the manuscript. All authors approved the manuscript.

\section{Conflicts of Interest}

None declared.

\section{References}

1. Arigbede A, Denloye O, Dosumu O. Use of simulators in operative dental education: experience in southern Nigeria. Afr Health Sci 2015 Mar;15(1):269-277 [FREE Full text] [doi: 10.4314/ahs.v15i1.35] [Medline: 25834558]

2. Perry S, Bridges SM, Burrow MF. A review of the use of simulation in dental education. Simul Healthc 2015 Feb;10(1):31-37. [doi: 10.1097/SIH.0000000000000059] [Medline: 25574865]

3. Coro Montanet G, Gómez Sánchez M, Suárez García A. Haptic simulators withvirtual reality environments in dental education: A preliminaryteaching diagnosis. @tic 2017 Jun 23(18):14-21. [doi: 10.7203/attic.18.9077]

4. Serrano CM, Wesselink PR, Vervoorn JM. First experiences with patient-centered training in virtual reality. J Dent Educ 2020 May;84(5):607-614. [doi: 10.1002/jdd.12037] [Medline: $\underline{31971611]}$

5. Xia P, Lopes AM, Restivo MT. Virtual reality and haptics for dental surgery: a personal review. Vis Comput 2012 Sep 8;29(5):433-447. [doi: 10.1007/s00371-012-0748-2]

6. Vannaprathip N, Haddawy P, Schultheis H, Suebnukarn S. Generating tutorial interventions for teaching situation awareness in dental surgery - preliminary report. 2017 Presented at: International Workshop on Multi-disciplinary Trends in Artificial Intelligence; 20-22 November; Gadong, Brunei Darussalam.

7. Pavaloiu I, Ioanitescu R, Dragoi G, Grigorescu S, Sandu S. Virtual reality for educationtraining in dentistry. In: eLearning and Software for Education. Bucharest: Carol I Natl Defence Univ Publishing House; 2016.

8. Freina L, Ott M. A literature review on immersive virtual reality in education: state of the art and perspectives. 2015 Presented at: The International Scientific Conference eLearning and Software for Education; April 2015; Bucharest (Romania) p. 23-24.

9. Ferguson MB, Sobel M, Niederman R. Preclinical restorative training. J Dent Educ 2002 Oct;66(10):1159-1162. [Medline: $\underline{12449210]}$ 
10. Rhienmora P, Haddawy P, Suebnukarn S, Dailey M. Providing objective feedback on skill assessment in a dental surgical training simulator. 2009 Presented at: Conference on Artificial Intelligence in Medicine in Europe; 18-22 July; Verona, Italy.

11. de Boer IR, Wesselink P, Vervoorn J. The creation of virtual teeth with and without tooth pathology for a virtual learning environment in dental education. Eur J Dent Educ 2013 Nov;17(4):191-197. [doi: 10.1111/eje.12027] [Medline: 24127759]

12. Luciano C, Banerjee P, DeFanti T. Haptics-based virtual reality periodontal training simulator. Virtual Reality 2009 Feb 13;13(2):69-85. [doi: 10.1007/s10055-009-0112-7]

13. de Boer IR, Bakker DR, Wesselink PR, Vervoorn JM. [The Simodont in dental education]. Ned Tijdschr Tandheelkd 2012 Jun;119(6):294-300. [doi: 10.5177/ntvt.2012.06.12105] [Medline: 22812267]

14. Escobar-Castillejos D, Noguez J, Neri L, Magana A, Benes B. A Review of Simulators with Haptic Devices for Medical Training. J Med Syst 2016 Apr;40(4):104. [doi: 10.1007/s10916-016-0459-8] [Medline: 26888655]

15. Wang D, Li T, Zhang Y, Hou J. Survey on multisensory feedback virtual reality dental training systems. Eur J Dent Educ 2016 Nov;20(4):248-260. [doi: 10.1111/eje.12173] [Medline: 26547278]

16. Jayaram S, Connacher HI, Lyons KW. Virtual assembly using virtual reality techniques. Computer-Aided Design 1997 Aug;29(8):575-584. [doi: 10.1016/S0010-4485(96)00094-2]

17. Steuer J. Defining Virtual Reality: Dimensions Determining Telepresence. J Commun 1992;42(4):73-93. [doi: 10.1111/j.1460-2466.1992.tb00812.x]

18. Ayoub A, Pulijala Y. BMC Oral Health 2019 Nov 08;19(1):238 [FREE Full text] [doi: 10.1186/s12903-019-0937-8] [Medline: 31703708 ]

19. Rolland J, Hua H. Head-Mounted Display Systems. 2005. URL: https://citeseerx.ist.psu.edu/viewdoc/download?doi=10. 1.1.465.4293\&rep=rep1\&type=pdf [accessed 2021-03-18]

20. Cruz-Neira C, Sandin D, Defanti T. Surround-screen projection-based virtual reality: the design and implementation of the CAVE. : Association for Computing Machinery; 1993 Presented at: 20th Annual Conference and Exhibition on Computer Graphics and Interactive Techniques; August 1993; Anaheim CA. [doi: 10.1145/166117.166134]

21. Cipresso P, Giglioli IAC, Raya MA, Riva G. The Past, Present, and Future of Virtual and Augmented Reality Research: A Network and Cluster Analysis of the Literature. Front Psychol 2018;9:2086 [FREE Full text] [doi: 10.3389/fpsyg.2018.02086] [Medline: 30459681]

22. Shahrbanian S, Ma X, Aghaei N, Korner-Bitensky N, Simmonds M. Use of virtual reality (immersive vs. non immersive) for pain management in children and adults: A systematic review of evidence from randomized controlled trials. Eur J Exp Biol 2012;2(5):1408-1422.

23. Vasco MAA, Souza JTAD, Las Casas EBD, de Castro e Silva ALR, Hecke M. A method for constructing teeth and maxillary bone parametric model from clinical CT scans. Computer Methods in Biomechanics and Biomedical Engineering: Imaging \& Visualization 2014 Mar 13;3(3):117-122. [doi: 10.1080/21681163.2014.889579]

24. Quan T, Han S, Cho H, Jeong W. Multi-GPU reconstruction of dynamic compressed sensing MRI. : Springer; 2015 Presented at: International Conference on Medical Image Computing and Computer-Assisted Intervention; Springer; 5-9 October 2015; Munich, Germany.

25. Lian C, Wang L, Wu T, Wang F, Yap P, Ko C, et al. Deep Multi-Scale Mesh Feature Learning for Automated Labeling of Raw Dental Surfaces From 3D Intraoral Scanners. IEEE Trans Med Imaging 2020 Jul;39(7):2440-2450. [doi: 10.1109/TMI.2020.2971730] [Medline: 32031933]

26. Gurusamy K, Aggarwal R, Palanivelu L, Davidson B. Virtual reality training for surgical trainees in laparoscopic surgery. Cochrane Database Syst Rev 2009 Jan 21(1):CD006575. [doi: 10.1002/14651858.CD006575.pub2] [Medline: 19160288]

27. Haluck RS, Webster RW, Snyder AJ, Melkonian MG, Mohler BJ, Dise ML, et al. A virtual reality surgical trainer for navigation in laparoscopic surgery. Stud Health Technol Inform 2001;81:171-176. [Medline: 11317733]

28. Riva G. Applications of virtual environments in medicine. Methods Inf Med 2003;42(5):524-534. [doi: 10.1055/s-0038-1634379] [Medline: 14654887 ]

29. de Boer IR, Lagerweij MD, de Vries MW, Wesselink PR, Vervoorn JM. The Effect of Force Feedback in a Virtual Learning Environment on the Performance and Satisfaction of Dental Students. Simul Healthc 2017 Apr;12(2):83-90. [doi: 10.1097/SIH.0000000000000208] [Medline: 28704286]

30. Wang D, Zhao X, Shi Y, Zhang Y, Hou J, Xiao J. Six Degree-of-Freedom Haptic Simulation of Probing Dental Caries Within a Narrow Oral Cavity. IEEE Trans Haptics 2016;9(2):279-291. [doi: 10.1109/TOH.2016.2531660] [Medline: 26915130]

31. Wang D, Shi Y, Liu S, Zhang Y, Xiao J. Haptic simulation of organ deformation and hybrid contacts in dental operations. IEEE Trans Haptics 2014 Mar;7(1):48-60. [doi: 10.1109/TOH.2014.2304734] [Medline: 24845745]

32. Kinoshita H, Nagahata M, Takano N, Takemoto S, Matsunaga S, Abe S, et al. Development of a Drilling Simulator for Dental Implant Surgery. J Dent Educ 2016 Jan;80(1):83-90. [Medline: 26729688]

33. Zhao X, Zhu Z, Cong Y, Zhao Y, Zhang Y, Wang D. Haptic Rendering of Diverse Tool-Tissue Contact Constraints During Dental Implantation Procedures. Front Robot AI 2020 Mar 20;7:35 [FREE Full text] [doi: 10.3389/frobt.2020.00035] [Medline: 33501203] 
34. Buchanan JA. Use of simulation technology in dental education. J Dent Educ 2001 Nov;65(11):1225-1231. [Medline: $\underline{11765868}$ ]

35. Roy E, Bakr MM, George R. The need for virtual reality simulators in dental education: A review. Saudi Dent J 2017 Apr;29(2):41-47 [FREE Full text] [doi: 10.1016/j.sdentj.2017.02.001] [Medline: 28490842]

36. Urbankova A. Impact of computerized dental simulation training on preclinical operative dentistry examination scores. J Dent Educ 2010 Apr;74(4):402-409. [Medline: 20388813]

37. Liu L, Zhou R, Yuan S, Sun Z, Lu X, Li J, et al. Simulation training for ceramic crown preparation in the dental setting using a virtual educational system. Eur J Dent Educ 2020 May;24(2):199-206. [doi: 10.1111/eje.12485] [Medline: 31766075]

38. Liu L, Li J, Yuan S, Wang T, Chu F, Lu X, et al. Evaluating the effectiveness of a preclinical practice of tooth preparation using digital training system: A randomised controlled trial. Eur J Dent Educ 2018 Nov;22(4):e679-e686. [doi: 10.1111/eje.12378] [Medline: 29952122]

39. Urbankova A, Engebretson SP. The use of haptics to predict preclinic operative dentistry performance and perceptual ability. J Dent Educ 2011 Dec;75(12):1548-1557. [Medline: 22184593]

40. Urbankova A, Eber M, Engebretson SP. A complex haptic exercise to predict preclinical operative dentistry performance: a retrospective study. J Dent Educ 2013 Nov;77(11):1443-1450. [Medline: 24192409]

41. Ben-Gal G, Weiss E, Gafni N, Ziv A. Testing manual dexterity using a virtual reality simulator: reliability and validity. Eur J Dent Educ 2013 Aug;17(3):138-142. [doi: 10.1111/eje.12023] [Medline: 23815690]

42. Steinberg AD, Bashook PG, Drummond J, Ashrafi S, Zefran M. Assessment of faculty perception of content validity of PerioSim, a haptic-3D virtual reality dental training simulator. J Dent Educ 2007 Dec;71(12):1574-1582. [Medline: 18096883]

43. Dangxiao Wang, Yuru Zhang, Jianxia Hou, Yong Wang, Peijun Lv, Yonggang Chen, Hui Zhao. iDental: A Haptic-Based Dental Simulator and Its Preliminary User Evaluation. IEEE Trans Haptics 2012;5(4):332-343. [doi: 10.1109/TOH.2011.59] [Medline: 26964131]

44. Wang F, Liu Y, Tian M, Zhang Y, Chen J. Application of a 3D Haptic Virtual Reality Simulation System for Dental Crown Preparation Training. 2017 Presented at: 8th International Conference on Information Technology in Medicine and Education (ITME); 23-25 Dec 2016; Fuzhou, China.

45. Eve EJ, Koo S, Alshihri AA, Cormier J, Kozhenikov M, Donoff RB, et al. Performance of dental students versus prosthodontics residents on a 3D immersive haptic simulator. J Dent Educ 2014 Apr;78(4):630-637. [Medline: 24706694]

46. Cormier J, Pasco D, Syllebranque C, Querrec R. VirTeaSy a haptic simulator for dental education. Bucharest: Bucharest University Press; 2011 Presented at: Proceedings of the 6th International Conference on Virtual Learning; Oct 28-29, 2011; Babes Bolyai Univ Cluj Napoca, Cluj Napoca, Romania.

47. Kim S, Min J, Kim H. The Development of an IoT-Based Educational Simulator for Dental Radiography. IEEE Access 2019;7:12476-12483. [doi: 10.1109/access.2019.2891569]

48. Pohlenz P, Gröbe A, Petersik A, von Sternberg N, Pflesser B, Pommert A, et al. Virtual dental surgery as a new educational tool in dental school. J Craniomaxillofac Surg 2010 Dec;38(8):560-564. [doi: 10.1016/j.jcms.2010.02.011] [Medline: 20303282]

49. Heiland M, Petersik A, Pflesser B, Tiede U, Schmelzle R, Höhne K. Realistic haptic interaction for computer simulation of dental surgery. Amsterdam: Elsevier; 2004 Presented at: The 18th International Congress and Exhibition on Computer Assisted Radiology and Surgery; June 23-26, 2004; Chicago, IL.

50. Nassar HM, Tekian A. Computer simulation and virtual reality in undergraduate operative and restorative dental education: A critical review. J Dent Educ 2020 Jul;84(7):812-829. [doi: 10.1002/jdd.12138] [Medline: 32147841]

51. Albuha Al-Mussawi RM, Farid F. Computer-Based Technologies in Dentistry: Types and Applications. J Dent (Tehran) 2016 Jun;13(3):215-222 [FREE Full text] [Medline: 28392819]

52. Quinn F, Keogh P, McDonald A, Hussey D. A study comparing the effectiveness of conventional training and virtual reality simulation in the skills acquisition of junior dental students. Eur J Dent Educ 2003 Nov;7(4):164-169. [doi: 10.1034/j.1600-0579.2003.00309.x] [Medline: 14753762]

53. Welk A, Splieth C, Rosin M, Kordass B, Meyer G. DentSim - a future teaching option for dentists. Int J Comput Dent 2004 Apr;7(2):123-130. [Medline: 15516090]

54. Dixon J, Towers A, Martin N, Field J. Re-defining the virtual reality dental simulator: Demonstrating concurrent validity of clinically relevant assessment and feedback. Eur J Dent Educ 2021 Feb;25(1):108-116. [doi: 10.1111/eje.12581] [Medline: 32780500]

55. Cheng A, Kessler D, Mackinnon R, Chang TP, Nadkarni VM, Hunt EA, International Network for Simulation-based Pediatric Innovation, Research, and Education (INSPIRE) Reporting Guidelines Investigators. Reporting Guidelines for Health Care Simulation Research: Extensions to the CONSORT and STROBE Statements. Simul Healthc 2016 Aug;11(4):238-248. [doi: 10.1097/SIH.0000000000000150] [Medline: 27465839]

56. Abe S, Noguchi N, Matsuka Y, Shinohara C, Kimura T, Oka K, et al. Educational effects using a robot patient simulation system for development of clinical attitude. Eur J Dent Educ 2018 Aug;22(3):e327-e336. [doi: 10.1111/eje.12298] [Medline: 29091328]

57. Jasinevicius TR, Landers M, Nelson S, Urbankova A. An evaluation of two dental simulation systems: virtual reality versus contemporary non-computer-assisted. J Dent Educ 2004 Nov;68(11):1151-1162. [Medline: 15520234] 
58. Polcar J, Horejsi P. Knowledge acquisition and cyber sickness: A comparison of VR devices in virtual tours. MM SJ 2015 Jun 03;2015(02):613-616. [doi: 10.17973/mmsj.2015 $06 \quad 201516$ ]

59. Jung H, Kim H, Moon S. Virtual reality training simulator for tooth preparation techniques. Oral Biol Res 2018 Dec 31;42(4):235-240. [doi: 10.21851/obr.42.04.201812.235]

60. Yamaguchi S, Kazumichi W, Yoshida Y, Nagashima T, Takeshige F, Kawamoto Y, et al. Dental haptic simulator to train hand skill of student - calibration method to realize visual haptic environment. Stud Health Technol Inform 2009;142:429-431. [Medline: 19377200]

61. Ruthenbeck GS, Reynolds KJ. Virtual reality for medical training: the state-of-the-art. Journal of Simulation 2017 Dec 19;9(1):16-26. [doi: 10.1057/jos.2014.14]

62. Keeve E, Girod S, Kikinis R, Girod B. Deformable modeling of facial tissue for craniofacial surgery simulation. Comput Aided Surg 1998;3(5):228-238. [doi: 10.1002/(SICI)1097-0150(1998)3:5<228::AID-IGS2>3.0.CO;2-I] [Medline: 10207647]

63. Mesit J, Guha R, Chaudhry S. 3D Soft Body Simulation Using Mass-spring System with Internal Pressure Force and Simplified Implicit Integration. JCP 2007 Oct 01;2(8):34-43. [doi: 10.4304/jcp.2.8.34-43]

64. Teschner M, Girod S, Girod B. Direct Computation of Nonlinear Soft-Tissue Deformation. URL: https://static.aminer.org/ pdf/PDF/000/647/215/direct computation of nonlinear soft tissue deformation.pdf [accessed 2021-03-18]

65. Nisansala A, Weerasinghe M, Dias G, Sandaruwan D, Kodikara N, Technology I. Soft tissue modeling techniques in surgery simulation. Int I Comput Inf Sci 2015;4(5):826-831.

66. Lazarski M, Susarla S, Bennett N, Seldin E. How do feedback and instructions affect the performance of a simulated surgical task? J Oral Maxillofac Surg 2007 Jun;65(6):1155-1161. [doi: 10.1016/j.joms.2006.11.021] [Medline: 17517300]

67. Wierinck E, Puttemans V, van Steenberghe D. Effect of tutorial input in addition to augmented feedback on manual dexterity training and its retention. Eur J Dent Educ 2006 Feb;10(1):24-31. [doi: 10.1111/j.1600-0579.2006.00392.x] [Medline: 16436081]

68. Espejo-Trung LC, Elian SN, Luz MAADC. Development and Application of a New Learning Object for Teaching Operative Dentistry Using Augmented Reality. J Dent Educ 2015 Nov;79(11):1356-1362. [Medline: 26522642]

69. Sabalic M, Schoener JD. Virtual Reality-Based Technologies in Dental Medicine: Knowledge, Attitudes and Practice Among Students and Practitioners. Tech Know Learn 2017 Feb 8;22(2):199-207. [doi: 10.1007/s10758-017-9305-4]

70. Kishimoto N, Mukai N, Honda Y, Hirata Y, Tanaka M, Momota Y. Simulation training for medical emergencies in the dental setting using an inexpensive software application. Eur J Dent Educ 2018 Aug;22(3):e350-e357. [doi: 10.1111/eje.12301] [Medline: 29120509]

71. Venkatesh V, Thong JYL, Xu X. Consumer Acceptance and Use of Information Technology: Extending the Unified Theory of Acceptance and Use of Technology. MIS Quarterly 2012 Mar;36(1):157-117. [doi: 10.2307/41410412] [Medline: 22217802]

72. González Bravo L, Fernández Sagredo M, Torres Martínez P, Barrios Penna C, Fonseca Molina J, Stanciu ID, et al. Psychometric analysis of a measure of acceptance of new technologies (UTAUT), applied to the use of haptic virtual simulators in dental students. Eur J Dent Educ 2020 Nov;24(4):706-714. [doi: 10.1111/eje.12559] [Medline: $\underline{32567797]}$

73. Quinn F, Keogh P, McDonald A, Hussey D. A study comparing the effectiveness of conventional training and virtual reality simulation in the skills acquisition of junior dental students. Eur J Dent Educ 2003 Nov;7(4):164-169. [doi: 10.1034/j.1600-0579.2003.00309.x] [Medline: 14753762 ]

74. Plessas A. Computerized Virtual Reality Simulation in Preclinical Dentistry: Can a Computerized Simulator Replace the Conventional Phantom Heads and Human Instruction? Simul Healthc 2017 Oct;12(5):332-338. [doi: 10.1097/SIH.0000000000000250] [Medline: 28697057]

75. Mirghani I, Mushtaq F, Allsop MJ, Al-Saud LM, Tickhill N, Potter C, et al. Capturing differences in dental training using a virtual reality simulator. Eur J Dent Educ 2018 Feb;22(1):67-71. [doi: 10.1111/eje.12245] [Medline: 27864856]

76. Imber S, Shapira G, Gordon M, Judes H, Metzger Z. A virtual reality dental simulator predicts performance in an operative dentistry manikin course. Eur J Dent Educ 2003 Nov;7(4):160-163. [doi: 10.1034/j.1600-0579.2003.00299.x] [Medline: 14753761]

77. Barsom EZ, Graafland M, Schijven MP. Systematic review on the effectiveness of augmented reality applications in medical training. Surg Endosc 2016 Oct;30(10):4174-4183 [FREE Full text] [doi: 10.1007/s00464-016-4800-6] [Medline: 26905573]

78. Schijven MP, Jakimowicz JJ. Validation of virtual reality simulators: Key to the successful integration of a novel teaching technology into minimal access surgery. Minim Invasive Ther Allied Technol 2005;14(4):244-246. [doi:

10.1080/13645700500221881] [Medline: 16754170 ]

79. van Ginkel MPH, Schijven MP, van Grevenstein WMU, Schreuder HWR. Bimanual Fundamentals: Validation of a New Curriculum for Virtual Reality Training of Laparoscopic Skills. Surg Innov 2020 Oct;27(5):523-533 [FREE Full text] [doi: 10.1177/1553350620953030] [Medline: $\underline{32865136]}$

80. Suebnukarn S, Phatthanasathiankul N, Sombatweroje S, Rhienmora P, Haddawy P. Process and outcome measures of expert/novice performance on a haptic virtual reality system. J Dent 2009 Sep;37(9):658-665. [doi: 10.1016/j.jdent.2009.04.008] [Medline: 19481326]

81. Gal GB, Weiss EI, Gafni N, Ziv A. Preliminary assessment of faculty and student perception of a haptic virtual reality simulator for training dental manual dexterity. J Dent Educ 2011 Apr;75(4):496-504. [Medline: 21460270] 
82. Seymour NE, Gallagher AG, Roman SA, O'Brien MK, Bansal VK, Andersen DK, et al. Virtual reality training improves operating room performance: results of a randomized, double-blinded study. Ann Surg 2002 Oct;236(4):458-63; discussion 463. [doi: 10.1097/00000658-200210000-00008] [Medline: 12368674]

83. Yin MS, Haddawy P, Suebnukarn S, Rhienmora P. Automated outcome scoring in a virtual reality simulator for endodontic surgery. Comput Methods Programs Biomed 2018 Jan;153:53-59. [doi: 10.1016/j.cmpb.2017.10.001] [Medline: 29157461]

84. Yamaguchi S, Yoshida Y, Noborio H, Murakami S, Imazato S. The usefulness of a haptic virtual reality simulator with repetitive training to teach caries removal and periodontal pocket probing skills. Dent Mater J 2013;32(5):847-852 [FREE Full text] [doi: 10.4012/dmj.2013-174] [Medline: 24088844]

85. Kim K, Cho J, Kim J, Park J. A Dental Simulator for Training of Prevalent Interventions: Tooth Restoration and Ultrasonic Scaling. Berlin, Heidelberg: Springer; 2012 Presented at: Haptics: Perception, Devices, Mobility, and Communication; 13-15 June 2012; Tampere, Finland.

86. Mladenovic R, Dakovic D, Pereira L, Matvijenko V, Mladenovic K. Effect of augmented reality simulation on administration of local anaesthesia in paediatric patients. Eur J Dent Educ 2020 Aug;24(3):507-512. [doi: 10.1111/eje.12529] [Medline: $\underline{32243051]}$

87. Maliha SG, Diaz-Siso JR, Plana NM, Torroni A, Flores RL. Haptic, Physical, and Web-Based Simulators: Are They Underused in Maxillofacial Surgery Training? Journal of Oral and Maxillofacial Surgery 2018 Nov;76(11):2424.e1-2424.e11. [doi: 10.1016/j.joms.2018.06.177] [Medline: 30081008]

88. Chen X, Sun P, Liao D. A patient-specific haptic drilling simulator based on virtual reality for dental implant surgery. Int J Comput Assist Radiol Surg 2018 Nov;13(11):1861-1870. [doi: 10.1007/s11548-018-1845-0] [Medline: 30097957]

89. Joseph D, Jehl J, Maureira P, Perrenot C, Miller N, Bravetti P, et al. Relative contribution of haptic technology to assessment and training in implantology. Biomed Res Int 2014;2014:413951 [FREE Full text] [doi: 10.1155/2014/413951] [Medline: 24701577]

90. Rodrigues MAF, Silva WB, Barbosa Neto ME, Gillies DF, Ribeiro IMMP. An interactive simulation system for training and treatment planning in orthodontics. Computers \& Graphics 2007 Oct;31(5):688-697. [doi: 10.1016/j.cag.2007.04.010]

91. Al-Saud L, Mushtaq F, Allsop M, Culmer P, Mirghani I, Yates E, et al. Feedback and motor skill acquisition using a haptic dental simulator. Eur J Dent Educ 2017 Nov;21(4):240-247. [doi: 10.1111/eje.12214] [Medline: 27324833]

92. Suebnukarn S, Hataidechadusadee R, Suwannasri N, Suprasert N, Rhienmora P, Haddawy P. Access cavity preparation training using haptic virtual reality and microcomputed tomography tooth models. Int Endod J 2011 Nov;44(11):983-989. [doi: 10.1111/j.1365-2591.2011.01899.x] [Medline: 21623838]

93. Lee SH. Research and development of haptic simulator for Dental education using Virtual reality and User motion. The International Journal of Advanced Smart Convergence 2018;6(4):114-120. [doi: 10.7236/IJASC.2018.7.4.114]

94. Serrano C, Wesselink PR, Vervoorn JM. [Real patients in virtual reality: the link between phantom heads and clinical dentistry]. Ned Tijdschr Tandheelkd 2018 May;125(5):263-267. [doi: 10.5177/ntvt.2018.05.17192] [Medline: 29754155]

95. Roy E, Quinsat VE, Bazin O, Lesclous P, Lejus-Bourdeau C. High-fidelity simulation in training dental students for medical life-threatening emergency. Eur J Dent Educ 2018 May;22(2):e261-e268. [doi: 10.1111/eje.12284] [Medline: 28833993]

96. Sararit N, Haddawy P, Suebnukarn S. Effectiveness of a low-cost VR simulator for emergency management training in dental surgery. : IEEE; 2018 Presented at: 2018 15th International Joint Conference on Computer Science and Software Engineering (JCSSE); 11-13 July 2018; Nakhonpathom, Thailand. [doi: 10.1109/JCSSE.2018.8457353]

97. Curnier F. Teaching dentistry by means of virtual reality--the Geneva project. Int J Comput Dent 2010;13(3):251-263. [Medline: 20879463]

98. LeBlanc VR, Urbankova A, Hadavi F, Lichtenthal RM. A preliminary study in using virtual reality to train dental students. J Dent Educ 2004 Mar;68(3):378-383. [Medline: 15038639]

99. Vincent M, Joseph D, Amory C, Paoli N, Ambrosini P, Mortier É, et al. Contribution of Haptic Simulation to Analogic Training Environment in Restorative Dentistry. J Dent Educ 2020 Mar;84(3):367-376. [doi: 10.21815/JDE.019.187] [Medline: 32176342]

100. Murbay S, Neelakantan P, Chang JWW, Yeung S. 'Evaluation of the introduction of a dental virtual simulator on the performance of undergraduate dental students in the pre-clinical operative dentistry course'. Eur J Dent Educ 2020 Feb;24(1):5-16. [doi: 10.1111/eje.12453] [Medline: 31278815]

101. Soto S, Luna J, Cano A. Big Data on Real-World Applications. London, UK: IntechOpen; 2016.

102. Seufert S, Meier C, Soellner M, Rietsche R. A Pedagogical Perspective on Big Data and Learning Analytics: A Conceptual Model for Digital Learning Support. Tech Know Learn 2019 Mar 1;24(4):599-619. [doi: 10.1007/s10758-019-09399-5]

103. Tang JKT, Xie H, Wong TL. A Big Data Framework for Early Identification of Dropout Students in MOOC. Berlin: Springer; 2015 Presented at: International Conference on Technology in Education; 2-4 July 2015; Hong Kong, China.

104. Shafi M, Molisch AF, Smith PJ, Haustein T, Zhu P, De Silva P, et al. 5G: A Tutorial Overview of Standards, Trials, Challenges, Deployment, and Practice. IEEE J. Select. Areas Commun 2017 Jun;35(6):1201-1221. [doi: 10.1109/jsac.2017.2692307]

105. Gupta A, Jha RK. A Survey of 5G Network: Architecture and Emerging Technologies. IEEE Access 2015;3:1206-1232. [doi: 10.1109/access.2015.2461602] 
106. Agiwal M, Roy A, Saxena N. Next Generation 5G Wireless Networks: A Comprehensive Survey. IEEE Commun Surv Tutorials 2016;18(3):1617-1655. [doi: 10.1109/comst.2016.2532458]

107. Vo N, Duong TQ, Tuan HD, Kortun A. Optimal Video Streaming in Dense 5G Networks With D2D Communications. IEEE Access 2018;6:209-223. [doi: 10.1109/access.2017.2761978]

108. Awobuluyi O, Nightingale J, Wang Q, Alcaraz-Calero J. Video Quality in 5G Networks: Context-Aware QoE Management in the SDN Control Plane. Piscataway, NJ: IEEE; 2015 Presented at: International Conference on Computer and Information Technology (CIT); 26-28 Oct. 2015; Liverpool, UK. [doi: 10.1109/CIT/IUCC/DASC/PICOM.2015.250]

109. Swetha S, Raj D. Optimized video content delivery over 5G networks. 2017 Presented at: 2017 2nd International Conference on Communication and Electronics Systems (ICCES); 19-20 Oct 2017; Coimbatore, India p. 1000-1002. [doi: 10.1109/CESYS.2017.8321232]

110. Raaen K, Kjellmo I. Measuring Latency in Virtual Reality Systems. Cham: Springer; 2015 Presented at: International Conference on Entertainment Computing; 29 September - 2 October; Trondheim, Norway.

111. Nightingale J, Salva-Garcia P, Calero JMA, Wang Q. 5G-QoE: QoE Modelling for Ultra-HD Video Streaming in 5G Networks. IEEE Trans on Broadcast 2018 Jun;64(2):621-634. [doi: 10.1109/tbc.2018.2816786]

112. Zheng H, Fang L, Ji M, Strese M, Ozer Y, Steinbach E. Deep Learning for Surface Material Classification Using Haptic and Visual Information. IEEE Trans Multimedia 2016 Dec;18(12):2407-2416. [doi: 10.1109/tmm.2016.2598140]

113. Wang S, Su Z, Ying L, Peng X, Zhu S, Liang F. Accelerating magnetic resonance imaging via deep learning. New York: IEEE; 2016 Presented at: 2016 IEEE 13th International Symposium on Biomedical Imaging (ISBI); 13-16 April 2016; Prague, Czech Republic p. 13.

114. Georgescu M, Ionescu RT, Verga N. Convolutional Neural Networks With Intermediate Loss for 3D Super-Resolution of CT and MRI Scans. IEEE Access 2020;8:49112-49124. [doi: 10.1109/access.2020.2980266]

115. Zuo Y, Jiang T, Dou J, Yu D, Ndaro ZN, Du Y, et al. A Novel Evaluation Model for a Mixed-Reality Surgical Navigation System: Where Microsoft HoloLens Meets the Operating Room. Surg Innov 2020 Apr;27(2):193-202. [doi: 10.1177/1553350619893236] [Medline: 31920155]

116. Ingeson M, Blusi M, Nieves J. Microsoft Hololens - A mHealth Solution for Medication Adherence. Cham: Springer; 2018 Presented at: International Workshop on Artificial Intelligence in Health; 13-14 July; Stockholm, Sweden.

117. Kwon H, Park Y, Han J. Augmented reality in dentistry: a current perspective. Acta Odontol Scand 2018 Oct;76(7):497-503. [doi: 10.1080/00016357.2018.1441437] [Medline: 29465283]

118. Azuma RT. A Survey of Augmented Reality. Presence: Teleoperators \& Virtual Environments 1997 Aug;6(4):355-385. [doi: $10.1162 /$ pres.1997.6.4.355]
Abbreviations
CAVE: Cave Automatic Virtual Environment
HMD: head-mounted display
IDEA: Individual Dental Education Assistant
IDEAL: Internet of Things-based education and learning
MRI: magnetic resonance imaging
RDTES: Real-time Dental Training and Evaluation System
VLNP: Virtual Learning Network Platform
VR: virtual reality

Edited by G Eysenbach; submitted 22.08.20; peer-reviewed by J Song, A Rung, P Kanzow; comments to author 06.09.20; revised
version received 26.11.20; accepted 29.01.21; published 08.04.21
Please cite as:
Li Y, Ye H, Ye F, Liu Y, Lv L, Zhang P, Zhang X, Zhou Y
The Current Situation and Future Prospects of Simulators in Dental Education
J Med Internet Res 2021;23(4):e23635
URL: $\underline{\text { https://www.jmir.org/2021/4/e23635 }}$
doi: $10.2196 / 23635$
PMID:

(C) Yaning Li, Hongqiang Ye, Fan Ye, Yunsong Liu, Longwei Lv, Ping Zhang, Xiao Zhang, Yongsheng Zhou. Originally published in the Journal of Medical Internet Research (http://www.jmir.org), 08.04.2021. This is an open-access article distributed under the terms of the Creative Commons Attribution License (https://creativecommons.org/licenses/by/4.0/), which permits unrestricted use, distribution, and reproduction in any medium, provided the original work, first published in the Journal of Medical Internet 
Research, is properly cited. The complete bibliographic information, a link to the original publication on http://www.jmir.org/, as well as this copyright and license information must be included. 